\title{
Evolução da Cadeia de Suprimentos da Indústria Automobilística no Brasil
}

\author{
Luis Felipe Roriz Scavarda \\ Sílvio Hamacher
}

\section{RESUMO}

Este artigo tem por objetivo descrever, caracterizar e analisar os efeitos das estratégias globais das companhias transnacionais na evolução da cadeia de suprimentos da indústria automobilística atuante no Brasil. Para isto, analisa-se a evolução desta cadeia com auxílio dos dados estatísticos da Associação Nacional dos Fabricantes de Veículos Automotores e do Sindicato Nacional da Indústria de Componentes para Veículos Automotores, à luz do referencial teórico sobre gestão da cadeia de suprimentos e considerando a realidade atual dos mecanismos de produção globalizados. Verificouse que essa evolução compreende momentos em que a cadeia apresentou elevado índice de nacionalização dos seus produtos e projetos, enquanto que em outros momentos este índice foi apenas parcial ou quase nulo. No contexto das mudanças ocorridas ao longo dos anos 90, o artigo examina de que forma estratégias globais, como fornecimento global, fornecimento acompanhando geograficamente o cliente, padronização de projetos e a adoção de plataformas mundiais estão influenciando as operações das montadoras de veículos e da indústria de autopeças atuantes no Brasil e na relevância do país na cadeia global de suprimentos.

Palavras-chaves: indústria automobilística; cadeia de suprimentos; globalização.

\begin{abstract}
The paper describes, characterizes and analyses the effects of the transnational companies' global strategies on the evolution of the automotive industry's supply chain. In order to achieve this goal, it analyses the evolution of this chain with the help of statistic data provided by the Brazilian associations for vehicle manufacturers and for the auto-part industry under the theoretical frame of reference of supply chain management and taking into consideration the present state of the global production mechanism. It will be shown that this evolution embraces periods that the chain presented a high level of nationalization of its products and projects, while in other periods this level was only partial or almost null. In the context of the changes during the 90 's, the paper examines the ways global strategies, like global sourcing, follow sourcing, carry over, and the adoption of global platforms are acting on the operation of the automotive assemblers and the auto-parts industry in Brazil, and on the relevance of this country in the global supply chain.
\end{abstract}

Key words: automotive industry; supply chain; globalization. 


\section{INTRODUÇÃO}

A década de 90 provocou profunda reflexão nos paradigmas sobre o desenvolvimento dos sistemas produtivos. A lógica de produção industrial, comercialização e relacionamento entre empresas e pessoas está sendo revista, acarretando mudanças substanciais na cadeia de suprimentos das indústrias. Novos desafios, oportunidades e ameaças estão sendo apresentados como conseqüência da globalização da cadeia, criando uma nova visão nas empresas que deixaram de operar de modo multidoméstico para atuar de forma integrada em todo o globo.

O presente artigo tem por objetivo descrever e analisar as formas de adaptação da cadeia de suprimentos da indústria automobilística no Brasil aos diferentes fatores internos e externos que afetaram esta cadeia. Para atingir este objetivo, foi realizada uma pesquisa descritiva, fundamentada na literatura publicada e nos dados fornecidos pela associações de fabricantes de veículos e de autopeças.

Para que seja possível analisar o atual cenário da cadeia de suprimentos da indústria automobilística no Brasil e compreender a relevância do Brasil no futuro da cadeia de suprimentos mundial, propõe-se inicialmente apresentar referencial teórico com considerações sobre a cadeia de suprimentos e o processo de globalização. Em seguida é descrita a evolução da cadeia de suprimentos da indústria automobilística no Brasil, focalizando a sua integração com os mercados externos. Posteriormente será analisado o novo cenário apresentado nos anos 90 , verificando-se então as condições de emergência da gestão da cadeia de suprimentos (SCM) e a inserção da cadeia brasileira nas estratégias globais da indústria automobilística. Na última seção são expostas as conclusões e as considerações finais dos autores.

\section{Quadro Conceitual}

\section{O Conceito de Cadeia de Suprimentos}

A cadeia de suprimentos é uma rede que engloba todas as empresas que participam das etapas de formação e comercialização de determinado produto ou serviço, que será entregue a um cliente final. Essas empresas podem ser de diversos tipos desempenhando diferentes responsabilidades na cadeia, desde a 
extração de um minério ou a manufatura de um componente, até a prestação de serviço logístico ou de vendas. Dependendo do seu produto, a companhia pode participar de diferentes cadeias.

De acordo com Slack (1993), a cadeia de suprimentos pode ser classificada em três níveis, rede total, rede imediata e rede interna, conforme apresentado na Figura 1.

Figura 1: Redes de Suprimentos Interna, Imediata e Total

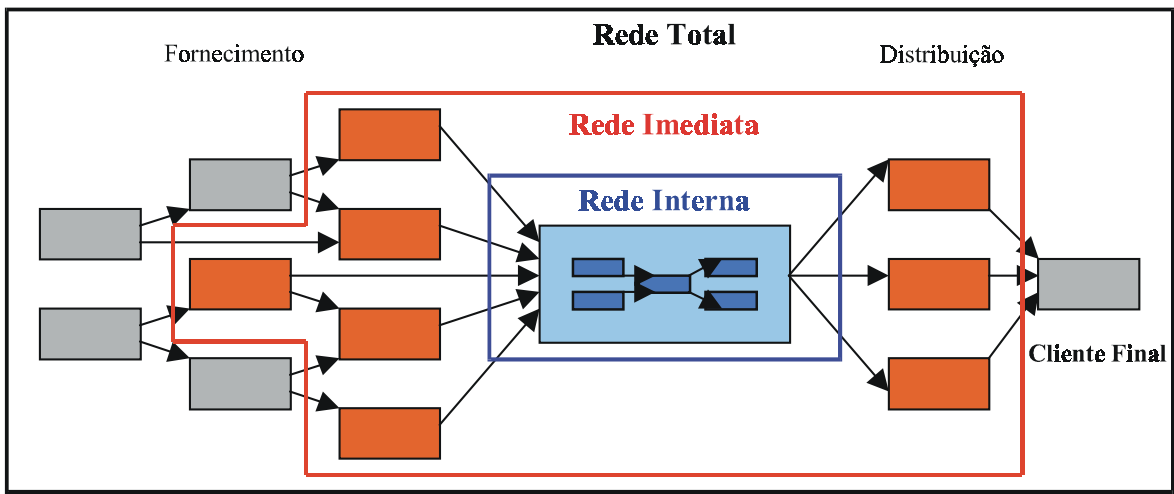

Fonte: Slack (1993).

. Rede interna: composta pelos fluxos de informações e de materiais entre departamentos, células ou setores de operação internos à própria empresa.

. Rede imediata: formada pelos fornecedores e clientes imediatos de uma empresa.

- Rede total: composta por todas as redes imediatas que compõem determinado setor industrial ou de serviços.

\section{A Gestão da Cadeia de Suprimentos}

Para Pires (1998) a gestão da cadeia de suprimentos pode ser considerada uma visão expandida, atualizada e, sobretudo, holística da administração de materiais tradicional, abrangendo a gestão de toda a cadeia produtiva de forma estratégica e integrada. A SCM pressupõe que as empresas devem definir as suas estratégias competitivas e funcionais por meio dos seus posicionamentos (tanto como fornecedores, quanto como clientes) dentro das cadeias produtivas nas quais se inserem. 
Wood e Zuffo (1998) afirmam que a SCM é uma forma de gestão desenvolvida para alinhar todas as atividades de produção de forma sincronizada, visando a reduzir custos, minimizar ciclos e maximizar o valor agregado por meio do rompimento das barreiras entre departamentos e áreas. Esta gestão é derivada da premissa segundo a qual a cooperação entre os membros da cadeia de suprimentos produz relacionamentos mais estáveis e duradouros, reduz os riscos individuais e melhora a eficiência do processo logístico, eliminando perdas e esforços desnecessários. Cada membro pertencente à cadeia deve agregar valor ao produto, e os processos que não fizerem isto devem ser alterados ou eliminados.

É importante notar que a SCM introduz uma interessante mudança no paradigma competitivo, na medida em que considera que a competição no mercado ocorre, de fato, no nível das cadeias produtivas, e não apenas no nível das unidades de negócios (isoladas), como estabelecia o tradicional trabalho de Porter. Essa mudança resulta em novo modelo competitivo, no qual as efetivas práticas da SCM visam a obter os benefícios da integração vertical, sem as desvantagens comuns em termos de custo e perda de flexibilidade inerentes à ela (Pires, 1998).

\section{A Cadeia de Suprimentos da Industria Automobilística}

A configuração da cadeia de suprimentos adotada neste artigo para a análise da indústria automobilística brasileira, assim como os seus principais componentes e produtos, podem ser sintetizados pela Figura 2. Além dos membros representados nessa figura, existem outros cuja participação é menos tangível, como os prestadores de serviço que também estão ligados ao sucesso da SCM, pois estão vinculados à coordenação dos fluxos de informação e de materiais entre os diversos membros da cadeia.

Para facilitar a análise da evolução da cadeia de suprimentos da indústria automobilística no Brasil, o fluxograma da Figura 2 é representado de forma simplificada na Figura 3. Cada membro da cadeia é simbolizado por um bloco no fluxograma, que poderá conter um fundo claro ou escuro. $\mathrm{O}$ fundo branco é adotado no artigo para os casos em que a maior parte das atividades produzidas pelo respectivo membro seja realizada no Brasil, enquanto que o fundo escuro indicará que estas etapas são elaboradas no exterior. A configuração da Figura 3, com todos os membros apresentados com fundo branco, é adotada nos casos em que todas as etapas de fabricação e comercialização de veículos forem realizadas em território nacional. 
Figura 2: A Estrutura da Cadeia de Suprimentos da Indústria Automobilística com os Principais Produtos e Componentes de cada Membro

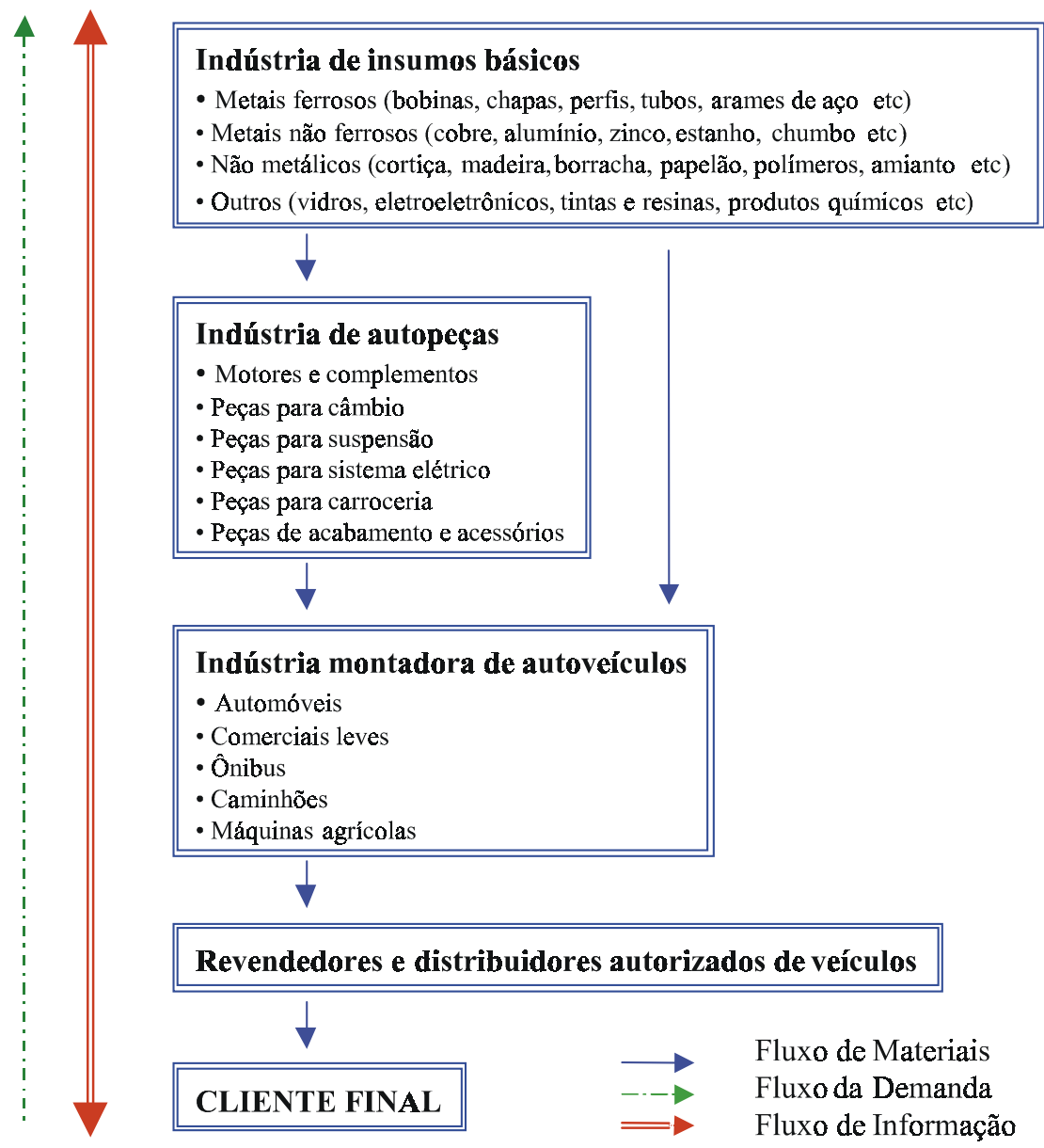

Fonte: adaptado de Bedê (1996).

Figura 3: Fluxograma da Cadeia de Suprimentos da Indústria Automobilística

\begin{tabular}{|c|c|c|c|c|}
\hline $\begin{array}{l}\text { Fornecedor } \\
\text { de insumos } \\
\text { básicos }\end{array}$ & $\begin{array}{l}\text { Fornecedor } \\
\text { de autopeças }\end{array}$ & $\begin{array}{c}\text { Indústria } \\
\text { montadora de } \\
\text { autoveículos }\end{array}$ & $\begin{array}{c}\text { Revendedores e } \\
\text { distribuidores } \\
\text { veículos }\end{array}$ & $\begin{array}{c}\text { CLIENTE } \\
\text { FINAL }\end{array}$ \\
\hline
\end{tabular}




\section{Considerações sobre o Processo de Globalização}

As atuais condições produtivas, tecnológicas, mercadológicas e gerenciais das indústrias atuantes no Brasil estão sendo afetadas de forma rápida, e freqüentemente irreversível, pelo processo de globalização. Essa nova realidade tem contribuído para o desenvolvimento de uma nova lógica industrial, em particular para a cadeia de suprimentos da indústria automobilística.

Para Fleury (1993) e Baumann (1996), o processo de globalização iniciou-se ainda nos anos 70 e o mundo já está presenciando o terceiro estágio da sua evolução. Depois da globalização das finanças, resultado da desregulamentação dos mercados financeiros e dirigida pelo avanço das tecnologias de computação e de telecomunicação, surgiu a globalização do comércio. Esse segundo estágio do processo de globalização foi intensificado com a redução das barreiras para comércio internacional e suportado pelo desenvolvimento de tecnologias de transporte. Com os anos 90, os sistemas produtivos e operacionais começaram a ser organizados de forma global, gerando uma lógica de produção completamente integrada. É nesse novo cenário que surge o terceiro e atual estágio do processo de globalização: a globalização da produção.

\section{A Evolução da Cadeia de Suprimentos da Indústria Automobilística No Brasil}

O entendimento da evolução da cadeia de suprimentos da indústria automobilística atuante no Brasil, é fundamental para melhor compreensão do seu atual cenário e para analisar o futuro do Brasil na cadeia de suprimentos mundial dessa indústria.

\section{Período até os Anos 50}

No início do século anterior, a única maneira de se adquirir um veículo no país era por meio da sua importação, normalmente elaborada por pessoas proeminentes na sociedade local, que emprestavam o seu prestígio pessoal ao negócio. Estes representantes das fábricas recebiam os pedidos, agilizavam a documentação, ofereciam garantias no ato da compra e atendiam a demanda no ritmo possível. Segundo a FENABRAVE (1998), estes indivíduos, denominados agentes, ainda não constituíam propriamente uma rede de distribuição, pois atuavam independentemente uns dos outros. 
Até este momento, a cadeia de suprimentos da indústria automobilística que tinha participação no Brasil era composta apenas pelo cliente final, conforme apresentado na Figura 4. Os agentes não desempenhavam o atual papel da distribuição, e os fornecedores de insumos básicos brasileiros colaboravam de maneira bastante indireta com a cadeia mencionada. Os demais membros da cadeia elaboravam as suas atividades no exterior, sendo representados por um fundo escuro em seus blocos no fluxograma da Figura 4.

\section{Figura 4: A Cadeia de Suprimentos das Primeiras Importações Brasileiras de Veículos}

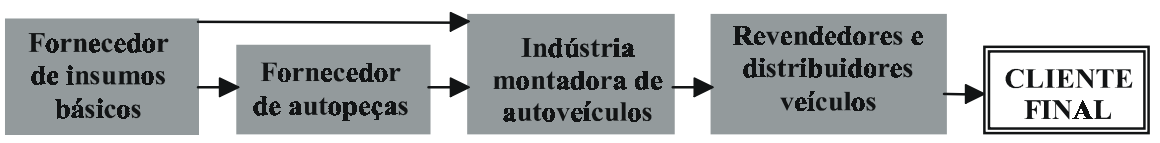

Dadas as condições mercadológicas atraentes que o Brasil demostrava durante as décadas de 20 e 30 e o seu limitado estágio tecnológico, que não permitia que as unidades fabris tivessem produção autônoma, algumas empresas resolveram instalar no país o sistema produtivo denominado completely knocked down (CKD), que significa completamente desmontado. As empresas que usavam o sistema CKD eram autênticas montadoras que utilizavam somente componentes importados. Elas recebiam os veículos desmontados em lotes de peças e componentes para depois montá-los. De acordo com a FENABRAVE (1998), a introdução deste sistema produtivo no Brasil teve as seguintes conseqüências:

. aumento da oferta de veículos de passeio e de pequenos caminhões;

- lançamento das bases para a fabricação nacional de carros, caminhões, furgões e ônibus;

. criação das condições para que, a partir dos anos 30, a indústria de autopeças pudesse se desenvolver;

- formação de mão-de-obra qualificada, condição necessária para que os agentes pudessem começar a prestar serviços de assistência técnica;

. estímulo para que as montadoras criassem as suas próprias redes de distribuição.

A criação das concessionárias implicou em novo sistema de relacionamento do fabricante com o seu distribuidor. $O$ distribuidor passou a receber do fabricante a concessão de comercializar e divulgar os seus produtos e de fornecer assistência técnica especializada. A partir deste momento, a cadeia de suprimentos da indústria automobilística no Brasil passou a contar com várias indústrias montadoras de automóveis instaladas no país, assim como uma rede de concessionárias res- 
ponsável pela distribuição de seus veículos. Com o desenvolvimento dessas atividades no Brasil, a cadeia de suprimentos brasileira passou a ter nova configuração, conforme apresentado na Figura 5.

\section{Figura 5: A Cadeia de Suprimentos da Indústria após a Introdução do CKD no Brasil}

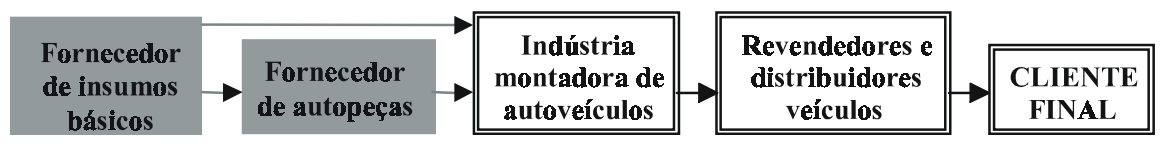

As criações da Companhia Siderúrgica Nacional (CSN) e da Fábrica Nacional de Motores (FNM), ambas nos anos 40, podem ser considerados marcos importantes para que o país pudesse produzir automóveis no final dos anos 50 .

\section{Período Compreendido entre os Anos 50 e 80}

Com o final da Segunda Guerra Mundial, as importações brasileiras atingiram valores muito elevados, especialmente as referentes à indústria automobilística, que na época representava o maior valor da pauta. Se as importações de matérias-primas já haviam sido parcialmente substituídas, como por exemplo o aço, chegava a vez de substituir as importações de bens duráveis, como os automóveis.

O esforço de substituição das importações iniciou-se com uma mudança no perfil das importações. A montagem de veículos no país passou de CKD para semi knocked down (SKD). Com o $\mathrm{SKD}$ agregou-se à montagem vários componentes feitos por fornecedores de autopeças atuantes no Brasil, como suporte de molas, cubos de rodas, tambores de freios, retentores, baterias, pneus e correias, entre outros.

Devido às diversas medidas políticas e econômicas do governo brasileiro durante a década de 50 para incentivar o programa de substituição das importações, grandes fabricantes mundiais de automóveis começaram a estabelecer fábricas no Brasil, produzindo assim os primeiros automóveis nacionais. As primeiras fábricas nasceram extremamente verticalizadas e com altíssimo índice de importação de componentes, pois na época ainda existia grande carência de indústrias de autopeças instaladas no país.

O constante aumento do índice de nacionalização nos veículos produzidos no país exigido pelo governo, fez com que fosse criada uma crescente rede industrial de fornecedores de autopeças. 
Com o estabelecimento da produção nacional de veículos e de autopeças no país, associada à produção manufatureira local de diversos insumos básicos, a indústria automobilística passou a produzir localmente todas os componentes da sua cadeia de suprimentos. Com isso, a configuração da cadeia passou a ser representada pela Figura 3, no qual os blocos no fluxograma de todos os participantes da cadeia possuem um fundo branco.

Até o início dos anos 70, essa cadeia industrial era totalmente voltada para o mercado nacional. A preocupação em inserir a cadeia no cenário internacional ocorreu ainda no anos 70 com o plano de Benefícios Fiscais a Programas Especiais de Exportação, o Befiex. Com ele, o Brasil iniciou um grande salto na exportação de veículos e de componentes para o mercado internacional, abrindo a porta para a sua inserção na cadeia mundial de suprimentos. De acordo com a ANFAVEA (1999), a exportação de veículos brasileiros passou de 25 unidades em 1969 para 73.101 em 1975.

O volume da produção anual de veículos, conforme apresentado na Figura 6, foi crescendo até o final da década de 70, apesar das eventuais crises no Brasil e no mundo, até atingir a marca de 1.000.000 de unidades produzidas em 1980.

\section{Figura 6: A Evolução da Produção de Veículos no Brasil}

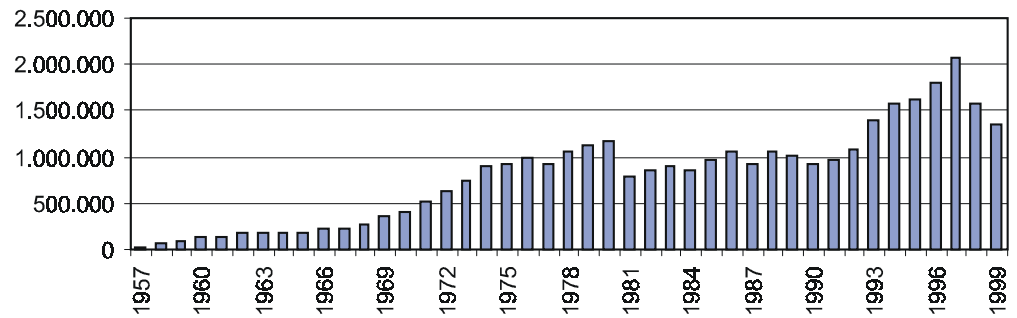

Fonte: ANFAVEA (1999).

A década de 80 foi um período de estagnação econômica no Brasil, afetando todo o seu setor industrial, inclusive a indústria automobilística, que registrou queda de produção da demanda local e de investimentos estrangeiros. Durante esta crise, a produção brasileira de veículos oscilou em torno de apenas 900.000 unidades anuais, conforme apresentado na Figura 6. Além da crise, as matrizes das indústrias instaladas no Brasil também passaram por dificuldades, devido ao avanço da indústria automobilística japonesa nos mercados da Europa e dos Estados Unidos. Com isso, todo o poder de investimento dessas matrizes foi destinado a estes mercados, deixando de fora as subsidiárias instaladas no Brasil, que foram obrigadas a adiar os seus planos de modernização, relegando assim o mercado brasileiro a um segundo plano. 
Este período também ficou marcado por certa autonomia que as subsidiárias brasileiras apresentaram em relação a suas matrizes localizadas no exterior. Isso repercutiu no desenvolvimento de estratégias próprias para o mercado brasileiro e de habilidades dentro do país, com a elaboração de diversos projetos nacionais.

\section{Período a Partir dos Anos 90}

Os anos 90 foram marcados no Brasil pela implantação de planos de estabilização econômica e de políticas governamentais específicas, como os acordos setoriais e multilaterais de comércio, a prática dos incentivos fiscais a novos investimentos oferecidos pelos estados e municípios e a redução dos impostos para os veículos produzidos no país, cuja motorização não excede $1.000 \mathrm{cc}$. Essas medidas foram a base política e econômica para a reestruturação da cadeia de suprimentos da indústria automobilística atuante no Brasil, contribuindo também para a elevação da demanda doméstica de veículos e para a modernização de toda a indústria.

A abertura econômica declarou o fim da fase de substituição das importações, que vigorava desde os anos 50, na qual a indústria automobilística atuante no Brasil operava em ambiente altamente protegido. Com isso, a cadeia dessa indústria atingiu o segundo estágio da globalização: a globalização do comércio. Em seguida teve início nova fase de inovação tecnológica e organizacional, itens que, combinados a crescente integração da cadeia aos mercados externos, trouxeram para o cotidiano industrial a necessidade de competir com produtos importados e de cooperar com parceiros internacionais da mesma cadeia. Estes fatores levaram à inclusão dessa cadeia no atual estágio do processo de globalização, a globalização da produção.

Este novo cenário brasileiro tem atraído novos investimentos em todos os setores da indústria automobilística brasileira, não só das empresas que já mantinham atividades no país, como também de diversos novos entrantes. Os principais investimentos estão concentrados no setor das montadoras de veículos e no de autopeças, e buscam ampliar a atual capacidade doméstica, além de modernizar as suas fábricas locais. Desde 1995 já foram investidos no país cerca de US\$10 bilhões pelas indústrias de autopeças e de US $\$ 15$ bilhões pelas montadoras de veículos. No caso das montadoras, as já estabelecidas como a Agrale, FIAT, Ford, GM, Mercedes, Scania, Toyota, Volkswagen e Volvo responderam pela maior parte do investimento, superando US $\$ 11$ bilhões. Os novos entrantes investiram de maneira mais tímida, com destaque para a Renault e, em seguida, para a PSA (Peugeot/Citröen). É válido mencionar que empresas já estabelecidas no país, como a Mercedes e a Toyota, diversificaram a sua atuação domés- 
tica, sendo agora também novos entrantes no segmento de mercado de veículos de passageiros.

O novo cenário brasileiro dos anos 90 também repercutiu nos números das exportações e importações de veículos e de autopeças no Brasil, conforme apresentado nas Figuras 7 e 8, respectivamente.

\section{Figura 7: Exportações e Importações de Veículos do Brasil}

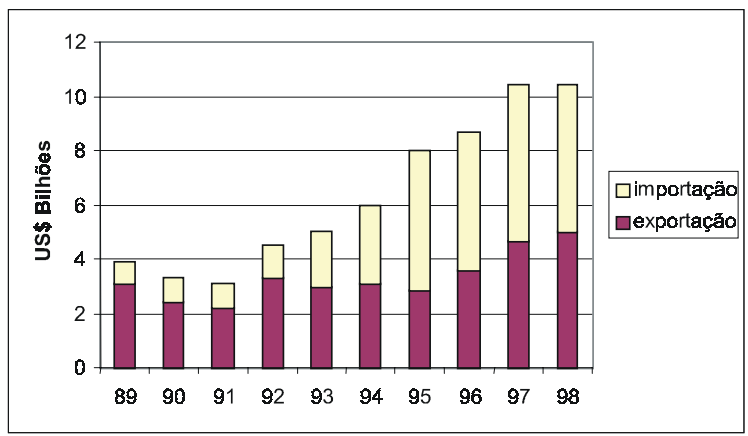

Fonte: ANFAVEA (1999) e SINDIPEÇAS (1999).

Figura 8: Exportações e Importações de Autopeças do Brasil

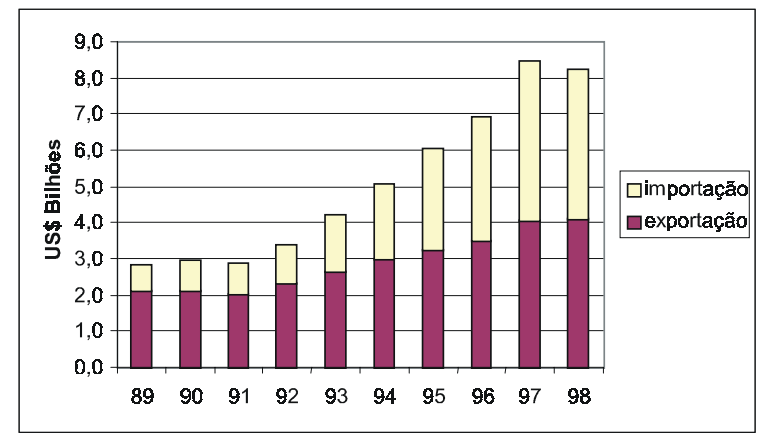

Fonte: ANFAVEA (1999) e SINDIPEÇAS (1999).

Com o novo cenário também ocorreram mudanças na configuração da cadeia de suprimentos dessa indústria no país. Cada membro dessa cadeia está adotando uma estratégia diferente para penetrar no Brasil, ou então para consolidar e defender a sua antiga posição de mercado. Isso se reflete na adoção de diferentes configurações de cadeia para cada um dos seus produtos. A subsidiária da Citröen no Brasil pode ser usada como exemplo. Atualmente, ela utiliza a sua planta uruguaia (Mercosul) para montar algumas versões do Xsara via CKD, e importa versões mais sofisticadas deste mesmo modelo da França. Ao mesmo 
tempo, a Citröen está estabelecendo uma fábrica no Brasil, atraindo diversos novos fornecedores de autopeças, consolidando assim a sua estratégia de penetração, e definindo uma configuração híbrida para a sua cadeia de suprimentos no Brasil.

Em suma, os anos 90 trouxeram uma mudança de visão nas operações de toda a indústria automobilística, e de multidoméstica ela passou a ser global. As diversas empresas pertencentes a rede total de suprimentos dessa indústria passaram a ter condições de ampliar e integrar os seus relacionamentos, não se limitando à globalização do comércio, evoluindo para a globalização da produção, gerando portanto a necessidade de introduzir uma SCM global. Dentro deste contexto, as perspectivas da cadeia da indústria automobilística atuante no Brasil serão analisadas na próxima seção.

\section{Perspectivas da Cadeia de Suprimentos no Brasil}

Com a globalização da produção, novas formas de relacionamentos e de gestão estão sendo desenvolvidas e estabelecidas na cadeia de suprimentos da indústria automobilística atuante no Brasil, de forma a torná-la mais competitiva. Essas mudanças estão ocorrendo principalmente com o intuito de adaptar e integrar essa cadeia às novas estratégias globais das montadoras de automóveis e da indústria de autopeças.

A seguir são descritos primeiramente os efeitos do terceiro estágio da globalização na gestão da cadeia de suprimentos, para depois serem analisados os efeitos das estratégias globais nos membros dessa cadeia.

\section{Novas Formas de Relacionamento e de Gestăo na Cadela}

Para se adequar à nova realidade dos anos 90, a indústria automobilística necessitou desenvolver mecanismos de contínua reestruturação de toda a sua cadeia de suprimentos. O mecanismo mais eficiente, que talvez englobe todos os demais, foi o de rever todos os relacionamentos dentro da cadeia, inclusive com o reforço das parcerias entre os seus membros (ou seja, com a divisão de responsabilidades), o que constitui o cerne da SCM. Em uma sociedade informatizada, o primeiro passo para reforçar parcerias e desenvolver o pensamento estratégico, inclusive gerando transparência no processo decisório, é a disseminação da informação. Para isso, os sistemas de informação passaram a ser vitais e parte integrante do ambiente de inovação, sendo usados como elementos de apoio na 
condução dos negócios, na integração de áreas produtivas e na relação com fornecedores e clientes.

De acordo com Miranda e Corrêa (1996), as empresas deste setor passaram a analisar com maior cuidado a dinâmica e complexidade da cadeia de suprimentos da qual fazem parte. Estas empresas continuam a trabalhar intensamente na sua rede de suprimentos imediata; porém já começam a conhecer e participar da operação da rede total, possibilitando assim uma administração mais efetiva dos seus membros imediatos. Em sua pesquisa, realizada com a participação de empresas atuantes no mercado automobilístico brasileiro, foi possível perceber que ainda existem vários problemas a serem superados, e que muitos deles dependem da ajuda dos elos mais fortes da cadeia. Cabe aos membros mais fortes a iniciativa do estabelecimento da SCM, uma vez que a essência desta gestão é a de detectar a fraqueza da cadeia e encontrar formas de diminuí-la. Um exemplo disto é o uso do maior poder de compra do membro mais forte para adquirir materiais e peças, com menor custo, para o seu fornecedor.

No caso da indústria automobilística, o elo mais forte é composto pelas montadoras de veículos; porém a sua atenção e influência ainda são basicamente voltadas para a sua rede imediata e não para a rede total de suprimentos. Apesar disto, mudanças no sentido de integrar a rede total estão ocorrendo em todos os membros da indústria automobilística, liderados principalmente pelas montadoras. Como exemplo pode-se citar a participação da Volkswagen no processo de compra de muitos dos seus fornecedores na sua nova fábrica de Resende (RJ). Esta participação ocorre quando a possibilidade de se fazer economia de escala neste processo pela montadora é maior que a do fornecedor, como acontece no caso da compra de amortecedores. Outro motivo para esta interferência da montadora é a falta de experiência no processo de compra de determinados componentes, como o que ocorre no módulo de tapeçaria desta fábrica, que tem como responsável a VDO. Esta empresa era especializada no fornecimento de instrumentos de medidas para veículos. Para que pudesse se transformar em modulista da Volkswagen, teve que adquirir novas competências na área de tapeçaria. Para isto ela está contando com o apoio e o know-how da montadora alemã. Neste caso específico, a interferência desta montadora não se limita apenas à rede imediata, obtendo redução no custo ao longo da rede total de suprimentos, podendo com isso reduzir o preço do seu produto final.

Segundo Miranda e Oliveira (1996), a maior mudança ocorrida na relação entre os membros da cadeia de suprimentos, tem se dado entre as indústrias montadoras de veículos e os fornecedores de autopeças. De acordo com Arbix e Zibovinicius (1997), estas mudanças já começam a ser vistas no desenvolvimento cooperativo de componentes, no aumento crescente da demanda por subsistemas completos de componentes para veículos, no fornecimento com parâmetros 
de qualidade mais intensos, na rigorosa seleção de fornecedores e na diminuição do seu número. Essas mudanças estão formando novas relações inter-firmas, e dando origem a novas estratégias competitivas dos produtores de autopeças.

O Brasil vem sendo utilizado como um laboratório para essa indústria no desenvolvimento de novas formas de gestão, como o Condomínio Industrial e o Consórcio Modular. São diversos os motivos para a adoção dessas novas formas de gestão; porém se obtido o sucesso esperado, elas deverão ser reproduzidas em outras fábricas da cadeia global dessa indústria.

\section{Efeitos das Estratégias Globais na Cadeia Atuante no Brasil}

Um novo cenário vem se estabelecendo com a concentração cada vez maior de atividades da indústria automobilística em regiões específicas do globo, na busca de maiores economias de escala. Essas atividades envolvem desde áreas relacionadas à gestão e produção industrial, até áreas como a de pesquisa e desenvolvimento $(\mathrm{P} \& \mathrm{D})$ das empresas. Esse cenário proporciona e influencia um novo conjunto de estratégias globais que vêm sendo adotadas e impostas a todos os membros da cadeia de suprimentos desta indústria, com enormes reflexos nas suas atividades desempenhadas no Brasil.

A estratégia do global sourcing consiste no fornecimento global por meio do menor número de fábricas possíveis, ampliando assim o mercado de algumas empresas de autopeças e expandindo as suas fronteiras geográficas. Essa estratégia, associada à estagnação em futuro próximo dos mercados europeu, americano e japonês e ao potencial de crescimento dos mercados dos países emergentes, está fazendo com que a indústria automobilística amplie a sua capacidade produtiva nestes países. Com isso, os países emergentes vêm ganhando importância estratégica nunca vista anteriormente na história recente da indústria automobilística mundial.

As Figuras 7 e 8 apresentaram o crescimento das importações e exportações de veículos e de autopeças. Esse crescimento confirma a tendência da adoção do global sourcing tanto por fábricas brasileiras no fornecimento para o resto do mundo, quanto por fábricas de outras localidades exportando para o Brasil.

Os elevados investimentos que vêm sendo feitos pelas montadoras de autoveículos no Brasil visam à alargar o mercado comprador e a base da sua cadeia de suprimentos, de forma a satisfazer principalmente as necessidades locais e as de outros países como os da América do Sul, principalmente os do Mercosul. A vinda destes novos investimentos está sendo acompanhada pelos fornecedores de autopeças globais, que são atraídos pelas potencialidades de 
crescimento do mercado brasileiro de forma direta, ou então de forma indireta, por meio do follow sourcing.

Salerno et al. (1998) descrevem as estratégias do follow sourcing e do carry over normalmente associadas ao global sourcing. O follow sourcing incentiva os fornecedores de primeira camada da cadeia a seguirem geograficamente as montadoras nos mercados onde os novos veículos são produzidos. No carry over o mesmo projeto é usado em todas as regiões e países onde o veículo será montado ou produzido, sem que se tenham mudanças nas características e nos atributos dos seus projetos. Esta estratégia reflete nos projetos dos veículos e dos seus componentes a busca pela economia de escala e objetivos comuns aos membros da cadeia de suprimentos.

Com a adoção dessas estratégias globais, as empresas transnacionais têm ampliado a sua participação e influência na cadeia de suprimentos da indústria automobilística. Como exemplo, pode-se analisar a indústria nacional de autopeças. As empresas dessa indústria estão tentando manter a sua participação no mercado doméstico, mas apenas algumas poucas estão conseguindo criar competências para penetrar no mercado global, passando assim a pertencer a cadeias globais de suprimentos. Fatores como os financeiros e tecnológicos, entre outros, estão fazendo com que muitos desses fornecedores percam participação no mercado doméstico, ficando inclusive restritos ao mercado de reposição, pois eles não conseguem atender aos requisitos necessários para o fornecimento dos novos modelos que estão agora sendo produzidos pelas montadoras no Brasil. A Figura 9 apresenta a influência dessas estratégias globais na indústria brasileira de autopeças mediante a comparação com as companhias de capital estrangeiro presentes no Brasil nos anos de 1994 e 1999. Pode-se ver que a participação das empresas nacionais diminuiu neste período de $52 \%$ para $31 \%$, tanto no valor do capital como no valor das autopeças vendidas. O crescimento do investimento estrangeiro é devido principalmente à adoção pelas empresas transnacionais de estratégias como o follow sourcing e o carry over.

Figura 9: A Internacionalização da Indústria de Autopeças no Brasil
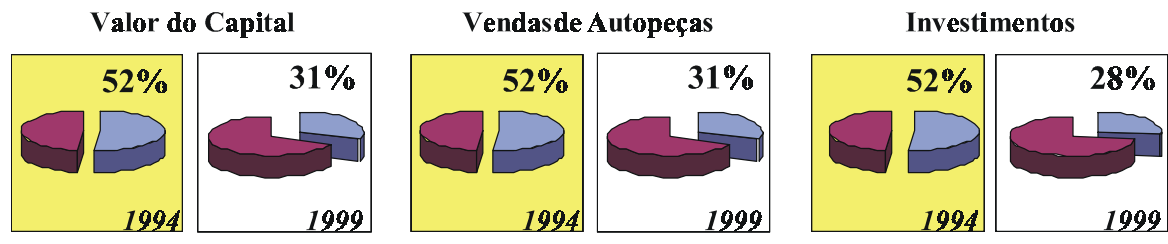

CapitalEstrangeiro

Capital Nacional

Fonte: SINDIPEÇAS (1999). 
A tendência de adotar plataformas mundiais pelas montadoras é outra estratégia global que também está influenciando a indústria automobilística atuante no Brasil. As montadoras passaram a produzir diversos modelos com a mesma plataforma, ampliando os seus ganho de escala, sem perder a necessária customização de cada modelo. Apesar dos recentes problemas de identidade envolvendo marcas e modelos de montadoras que vêm adotando intensamente essa estratégia, as reduções de custos associados a ela são imprescindíveis para o sucesso a médio prazo das montadoras. No Brasil o reflexo dessa estratégia pode ser visto como um dos responsáveis pela renovação rápida dos modelos produzidos nacionalmente, e também pelo provável fim do veículo de projeto nacional. A família Gol ainda sobrevive; porém os seus dias estão contados, pois a Volkswagen irá substituí-la em breve por novo modelo baseado na plataforma mundial do VW Polo. Essa mesma plataforma também é responsável pela produção dos modelos Arosa, Ibiza e Cordoba da Seat e do VW Lupo, possuíndo uma produção mundial de cerca de 1.000.000 de veículos. Espera-se com a nova família Gol que esse número chegue perto de 1.500 .000 de unidades por ano.

\section{Conclusóes e Consideraçóes finais}

As mudanças que vêm ocorrendo na cadeia de suprimentos da indústria automobilística atuante no Brasil não são casos particulares de uma região. As empresas pertencentes à cadeia mundial dessa indústria estão no momento sofrendo a mesma pressão: elas devem concorrer em mercados globais e, portanto, capazes de fornecer, de forma competitiva, diversos produtos para diferentes regiões do mundo. As montadoras estão atingindo esse objetivo por meio de estratégias globais e da adoção de sistemas e subsistemas modulares. Para tal, as montadoras necessitam de fornecedores integrados, capazes de produzir componentes onde elas estiverem e quando elas precisarem, requerendo assim uma SCM global. Os projetos e as tecnologias devem ser globais, mas totalmente integrados às operações locais.

Com o desenvolvimento de estratégias globais, a escala mínima necessária para a produção local foi elevada, de forma a reduzir custos para competir globalmente. Para isso, a produção brasileira de veículos e de autopeças deverá não somente atender o seu mercado doméstico, como também o mercado de outros países, principalmente os sul-americanos. Por outro lado, essa produção local deverá conviver e competir no país com produtos importados.

O Brasil possui atualmente número elevado de montadoras estabelecidas localmente. Este quadro poderá ser alterado, visto que a médio prazo provavelmente 
não existirá a escala mínima de produção necessária para tantos fabricantes no país. É possível que, com o final do período de incentivos fiscais dados pelos diversos governos municipais e estaduais, algumas fábricas terminem as suas operações locais, para concentrá-las em outras regiões onde elas possam conseguir a desejada escala. Esse fenômeno, conhecido como shake-out, obrigará muitos países emergentes a concorrer entre si para manter as suas fábricas locais, e com isso o emprego de muitos dos seus habitantes.

No nível produtivo, o atual cenário brasileiro é bastante favorável devido à sua localização, pois é uma porta de entrada para o mercado sul-americano; à dimensão do seu mercado interno, que tende a crescer e a se recuperar da atual crise econômica; e ao seu baixo custo de produção, favorecido pela desvalorização do Real, o que está proporcionado perspectivas favoráveis para a exportação de veículos e de auto-peças.

Contudo existe uma tendência de concentração das atividades como as de P\&D nas matrizes mundiais das empresas. Num primeiro cenário, o país pode ser obrigado a se limitar a atividades produtivas, deixando-o com menor importância na cadeia. Neste caso, o futuro da indústria automobilística no Brasil seria incerto, em função de provável shake-out entre as numerosas novas fábricas existentes nos países emergentes e pela fácil mobilidade das fábricas atuais, quase reduzidas a montadoras de peças, que podem a qualquer momento se estabelecer em uma outra região ou país que lhes ofereça maiores vantagens para a produção de veículos.

Num cenário otimista, o país pode manter atividades de pesquisa e desenvolvimento, cujas habilidades já foram adquiridas no passado, adicionando maior valor agregado de suas atividades na cadeia global. Uma possível alternativa para desenvolver atividades de maior valor agregado na cadeia seria a de complementar as atividades de $\mathrm{P} \& \mathrm{D}$ mundiais. Algumas possibilidades de desenvolvimento de projetos nacionais podem ser destacadas: adaptação de projetos globais para atender melhor as necessidades locais, como a customização da plataforma mundial do VW Polo para o desenvolvimento do novo Gol; aproveitamento do know-how local para cooperar e gerar produtos globais, como o caso da fabricação de caminhões em Resende pela VW; e o desenvolvimento de novas metodologias produtivas em escala reduzida, para depois reproduzi-las em outros países com escala maior. Mesmo com essas possibilidades, o futuro do Brasil em áreas como $\mathrm{P} \& \mathrm{D}$ é ainda bastante incerto devido à tendência quase generalizada de manter as pesquisas junto à matriz em apenas um local do mundo.

A análise realizada neste artigo limitou-se ao caso do Brasil; mas pesquisas futuras deverão estabelecer a correlação da evolução da cadeia de suprimentos da indústria automobilística com a de outros países emergentes, procurando esta- 
belecer as principais estratégias adotadas pelas montadoras nestes países. Especial atenção deve ser dada ao estudo do caso do Mercosul, em função da importância da complementaridade industrial entre seus membros e da adoção de estratégias integradas para os países desta região.

\section{ReferénCias Bibliográficas}

\section{ANFAVEA.}

Anuário estatístico da indústria automobilística brasileira. São Paulo : ANFAVEA,1999.

ARBIX, G.;

ZIBOVINICIUS, M.

O consórcio modular da VW : um novo modelo de produção? In: . (Orgs.). De JK a FHC : a reinvenção dos carros. São Paulo : Scritta, 1997.

BAUMANN, R.

O Brasil na economia global. Rio de Janeiro : Campus, 1996.

BEDÊ, M. A.
A indústria automobilística no Brasil nos anos 90 : proteção efetiva, reestruturação e política industrial. São Paulo, 1996. Tese (Doutorado em Ciências Econô- micas) - Universidade de São Paulo.

FENABRAVE.

A distribuição de veículos no Brasil. Relatório de Pesquisa Histórica, São Paulo, 1998.

FLEURY, A.

The changing pattern of operations management in developing countries. International Journal of Operations \& Production Management, v. 19, n. 5/6, p. 552-564, 1993.

MIRANDA, N. G. M.;

CORRÊA, H. L.

Uma análise parcial da rede de suprimentos da indústria automobilística brasileira vista da administração. Revista de Administração, v. 31, n. 1, 1996.

MIRANDA, S. M.;

OLIVEIRA, D. R.

Globalização e setor automotivo : a visão dos trabalhadores. São Paulo : [s.n.], 1996. 
PIRES, S. R. I.

Managerial implications of the modular consortium model in a Brazilian automotive plant. International Journal of Operations \& Production Management, v. 18, n. 3, p. 221232, 1998 .

SALERNO, M. S. et al.

Mudanças e persistências no padrão de relações entre montadoras e autopeças no Brasil. Revista de Administração, v. 33, n. 3, p. 16-28, 1998.
SINDIPEÇAS.

Desempenho do setor de autopeças São Paulo : ABIPEÇAS-SINDIPEÇAS, 1999.

SLACK, N.

Vantagem competitiva em manufatura. São Paulo : Atlas, 1993.

WOOD, T.;

ZUFFO, P. K.

Supply chain management. Revista de Administração de Empresas, v. 38, n. 3, p. 55-63, 1998. 